\title{
Sanguinarine is a novel VEGF inhibitor involved in the suppression of angiogenesis and cell migration
}

\author{
JIA-YING XU ${ }^{1}$, QING-HUI MENG ${ }^{2}$, YU CHONG $^{1}$, YANG JIAO $^{1}$, LIN ZHAO $^{1}$, ELIOT M. ROSEN $^{2}$ and SAIJUN FAN ${ }^{1}$ \\ ${ }^{1}$ School of Radiation Medicine and Protection, Medical College of Soochow University, Suzhou, Jiangsu 215123, P.R. China; \\ ${ }^{2}$ Department of Oncology, Lombardi Comprehensive Cancer Center, Georgetown University, Washington, DC 20057, USA
}

Received May 9, 2012; Accepted September 26, 2012

DOI: $10.3892 / \mathrm{mco} .2012 .41$

\begin{abstract}
Vascular endothelial growth factor(VEGF) is a main angiogenic factor which is known to be upregulated in lung cancer. In the present study, it was demonstrated that sanguinarine, an alkaloid obtained from the bloodroot plant, markedly repressed the VEGF-induced tube formation of human microvascular endothelial cells (HMVECs) and the migration of human A549 lung cancer cells. Furthermore, sanguinarine decreased VEGF secretion and expression in HMVECs and A549 lung cancer cells in a dose- and time-dependent manner. Additionally, sanguinarine inhibited the activation of serum starvation- and hypoxia-induced VEGF promoter activity. Sanguinarine also inhibited the VEGF-mediated Akt and p38 activation, as well as VE-cadherin protein phosphorylation. To the best of our knowledge, this is the first study demonstrating that VEGF inhibition appears to be an important mechanism involved in the antiangiogenic and anti-invasive activities of sanguinarine in lung cancer treatment.
\end{abstract}

\section{Introduction}

Vascular endothelial growth factor (VEGF) is one of the most potent and specific regulators in physiological angiogenesis and is an important stimulator of tumor-associated neovascularization $(1,2)$. Angiogenesis also is essential for tumor progression and metastasis. VEGF is expressed in the majority of solid tumors, including lung cancer, and its overexpression is associated with a poor prognosis $(3,4)$. It has been demonstrated that the VEGF pathway can be inhibited by either targeting VEGF directly or inhibiting VEGF receptors. VEGF inhibition is correlated with the suppression of lung cancer growth and angiogenesis (4-7). Therefore, angiogenesis and VEGF are important targets for the treatment of lung cancer.

Correspondence to: Dr Saijun Fan, School of Radiation Medicine and Protection, Medical College of Soochow University, 199 Ren Ai Road, Suzhou Industric Park, Suzhou, Jiangsu 215123, P.R. China E-mail: sjfan@suda.edu.cn

Key words: sanguinarine, vascular endothelial growth factor, human microvascular endothelial cells, lung cancer cells
Sanguinarine is a benzophenanthridine alkaloid derived from the root of Sanguinaria canadensis and other poppy-fumaria species, and has been shown to possess antimicrobial, antioxidant and anti-inflammatory properties (8). An increasing number of studies have suggested that sanguinarine at micromolar concentrations exhibits potential antitumor activities by the inhibition of cancer cell growth, migration and invasion, as well as the repression of angiogenesis (9-12). Additional studies have indicated that sanguinarine reduces VEGF-induced angiogenesis (13-15). Moreover, the inhibition of angiogenesis by sanguinarine has recently been validated in melanoma (10) and colorectal cancer (17). However, the exact, intracellular molecular-targeted protein of sanguinarine on angiogenesis remains to be elucidated, although VEGF-induced Akt phosphorylation has previously been described (15). The aim of this study, was to investigate the direct impacts of sanguinarine on VEGF secretion, expression and activation.

\section{Materials and methods}

Cell lines and reagents. Human microvascular endothelial cells (HMVECs) were cultured in MCDB-131 medium containing basic fibroblast growth factor, heparin, fetal calf serum (FCS), penicillin, streptomycin and amphotericin-B (Sigma-Aldrich, St. Louis, MO, USA) in tissue culture dishes pre-coated with $1.5 \%$ gelatin in phosphate-buffered saline (PBS). Human A549 lung cancer cells were obtained from the American Type Culture Collection (Manassas, VA, USA) and routinely cultured in RPMI-1640 medium containing 10\% heat-inactivated FCS, penicillin and streptomycin. Recombinant human VEGF was purchased from R\&D Systems (Minneapolis, MN, USA). Sanguinarine chloride was purchased from Sigma-Aldrich, dissolved in dimethyl sulfoxide (DMSO) and stored at $-20^{\circ} \mathrm{C}$.

Tubeformation assay. HMVECs from passages 5-8 were seeded on Matrigel-coated 24-well plates to form confluent monolayers. Following the stimulation, of monolayers in medium containing VEGF $(30 \mathrm{ng} / \mathrm{ml}) \pm$ sanguinarine for $48 \mathrm{~h}, \mathrm{HMVECs}$ were fixed with $0.5 \mathrm{ml}$ of glutaraldehyde/paraformaldehyde mixture $(2.5 \%)$ and stained with modified May-Gruenwald solution $(0.25 \%)$. Tubular structure formations were visualized with a Zeiss Axiovert 200 microscope and photomicrographs were documented by a Nikon CoolPix digital camera (Tokyo, 
Japan). Recorded images were assessed for the number and total length of tube formation. Tube formation was defined as straight cellular extensions joining two cell masses or at branch points. At least 10 random fields/wells were used for the assessment of angiogenesis.

Assay of VEGF secretion. The conditioned media were collected from confluent cultures of either HMVECs or A549 cells exposed to different concentrations of sangunarine and centrifuged. VEGF concentrations were then determined using a quantitative ELISA kit, according to the manufacturer's instructions (R\&D Systems). The amount of VEGF immunoreactivity was calculated using recombinant human VEGF standards present on each plate. Optical densities were determined at $450 \mathrm{~nm}$ using a spectrophotometer.

Migration assay. A549 cells were seeded into fibronectin (16 mg/ml)-coated 6-well tissue culture dishes at a concentration of $2.5 \times 10^{5}$ cells and cultured to almost confluent cell monolayers, which were then wounded using 200- $\mu$ l sterile pipette tips and any cellular debris was carefully removed by washing with PBS. The wounded monolayers were incubated in medium containing $30 \mathrm{ng} / \mathrm{m} \pm 1.0$ or $1.5 \mu \mathrm{M}$ sanguinarine for $24 \mathrm{~h}$ and photographed under a light microscope. The experiments were repeated in quadruplicate wells at least three times (magnification, x100).

Northern blot analysis. Briefly, total RNA extracted from cells was performed using TRIzol reagent (Invitrogen, Carlsbad, CA, USA). Thirty micrograms of each RNA sample were subjected to electrophoresis on $1 \%$ denaturing formaldehyde-agarose gels, blotted onto nylon membrane overnight by capillary transfer, and UV cross-linked by a UV Stratalinker 1800 (Stratagene, La Jolla, CA, USA). The blots were pre-hybridized in rapid hybridization buffer for $4 \mathrm{~h}$ and then hybridized overnight at $42^{\circ} \mathrm{C}$ with a human VEGF cDNA probe radiolabeled with $(\alpha-32 \mathrm{P}) \mathrm{dCTP}$ in a standard random-primed reaction to a specific activity of $1-2 \times 10^{9} \mathrm{cpm} / \mu \mathrm{g}$. As probe, we used an 800-bp DNA fragment, which hybridizes to the first exon of the human VEGF gene, and an 800-bp Pst I fragment of the mouse $\beta$-actin gene. Hybridization was performed in QuikHyb solution (Stratagene) and was washed completely. Autoradiography was performed at $-80^{\circ} \mathrm{C}$ for 3 days. The filters were stripped and re-probed with $\beta$-actin to normalize for RNA loading.

Assay of luciferase reporter activity. As described in our previous study (18), subconfluent A549 cells in 24-well tissue culture dishes were transfected with pGL3 (as the negative control) or pGL3-VEGF reporter plasmids using Lipofectamine $^{\mathrm{TM}} 2000$ transfection reagent (Invitrogen) according to the manufacturer's protocol. The total transfected DNA was kept constant by the addition of a control vector. Cells were incubated in medium containing various concentrations of VEGF for $24 \mathrm{~h}$, and harvested for the luciferase assays. To assess transfection efficacy, pRSV- $\beta$-gal plasmid was co-transfected to allow normalization of luciferase values to $\beta$-galactosidase activity in the same sample.

Western blot analysis. As described in our previous study (18), cells were harvested and lysed on ice for $20 \mathrm{~min}$ with ice-cold lysis buffer [150 mM NaCl, $10 \mathrm{mM}$ Tris- $\mathrm{HCl}(\mathrm{pH} 7.5), 1 \%$ Triton X-100, $1 \mathrm{mM}$ vanadate, $10 \mu \mathrm{g} / \mathrm{ml}$ leupeptin, $10 \mu \mathrm{g} / \mathrm{ml}$ aprotinin, $1 \mathrm{mM}$ phenylmethylsulfonyl fluoride, $0.36 \mathrm{mM}$ phenanthroline]. The lysates were centrifuged for $10 \mathrm{~min}$ at $4^{\circ} \mathrm{C}$, and the supernatant was collected. Total protein $(100 \mu \mathrm{g})$ was boiled in Laemmli sample buffer (125 mM Tris-HCl, pH 6.8, $20 \%$ glycerol, $4 \%$ SDS, $10 \% \beta$-mercaptoethanol and $0.00125 \%$ bromophenol blue), separated by SDS-PAGE in $10 \%$ gel and transferred onto $0.2 \mu \mathrm{m}$ nitrocellulose membrane by electroblotting. The membrane was blocked with $0.3 \%$ bovine serum albumin (BSA) in PBS containing 0.1\% Tween-20 and probed with polyclonal antibody against protein kinase $\mathrm{C}$ (PKC) for $2 \mathrm{~h}$ at room temperature at $4^{\circ} \mathrm{C}$. Immunoreactive bands were visualized after an 1-h incubation with horseradish peroxidase-conjugated anti-mouse antibody, followed by ECL ${ }^{\mathrm{TM}}$ Western blot detection system. Anti-pSer473 Akt, anti-Akt, anti-p38 and anti-VE-cadherin antibodies used in the study were purchased from Cell Signaling Technology, Inc. (Beverley, MA, USA). Polyclonal anti-pTyr658 VE-cadherin and anti-p-Tyr731 VE-cadherin were obtained from EMD Millipore Co. (Billerica, MA, USA). Anti-pTyr182 p38 antibody and anti-p-Tyr685 VE-cadherin antibody were purchased from Santa Cruz Biotechnology, Inc. (Santa Cruz, CA, USA) and BD Biosciences (San Jose, CA, USA), respectively.

\section{Results}

Inhibitory effects of sanguinarine on VEGF-induced angiogenesis and migration. As shown in Fig. 1A, VEGF-induced tubular structure formation of HMVECs was markedly repressed when HMVECs were cultured in medium supplemented with sanguinarine at $0.25,0.5,1.0$ and $1.5 \mu \mathrm{M}$ for $24 \mathrm{~h}$, resulting in an $18,53,71$ and $82 \%$ reduction, respectively. These findings are in agreement with those of previous studies (13-16), suggesting that sanguinarine is a potent inhibitor of VEGF-mediated angiogenesis.

To examine whether or not sanguinarine affects the migration of lung cancer cells, a scratch wound assay was performed. Confluent monolayers of A549 cells were scratch wounded with sterile pipette tips and post-incubated for $24 \mathrm{~h}$ in medium containing VEGF \pm sanguinarine $(0.5$ or $1.0 \mu \mathrm{M}$; Fig. 1B). In the presence of VEGF, A549 cells rapidly migrated along the edges of the wound and covered the wound, whereas a significant inhibition of cell flattening and spreading was observed in the presence of 0.5 or $1.0 \mu \mathrm{M}$ sanguinarine. These findings indicate that sanguinarine at non-toxic concentrations significantly suppressed A549 cell migration.

Inhibition of VEGF secretion by sanguinarine. Compared to untreated cells, sanguinarine caused a significant dose- and time-dependent inhibition of VEGF secretion in both HMVEC and A549 cells at all the concentrations examined (Fig. 2). For example, $0.25,0.5$ and $1 \mu \mathrm{M}$ sanguinarine resulted in an $\sim 40,53$ and $80 \%$ reduction of VEGF secretion induced by serum starvation in A549 cells at $24 \mathrm{~h}(\mathrm{P}<0.05)$, while $1 \mu \mathrm{M}$ sanguinarine induced an $\sim 84,80,66,58$ and $60 \%$ reduction at $8,16,24,32$ and $48 \mathrm{~h}$, respectively $(\mathrm{P}<0.05)$.

Inhibition of VEGF transcripts by sanguinarine. Exponentially growing A549 cells were cultured in serum-free medium with 
A

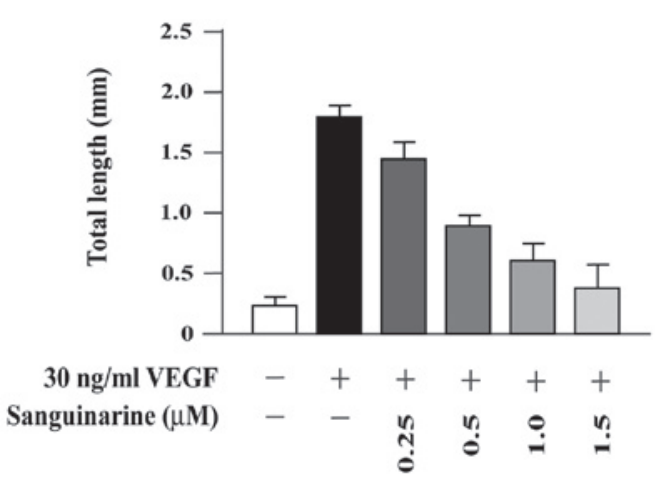

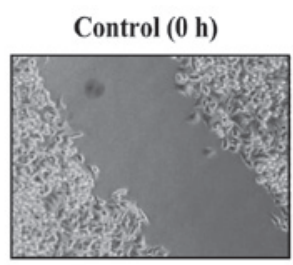

Sanguinarine $(0.5 \mu \mathrm{M}, 24 \mathrm{~h})$

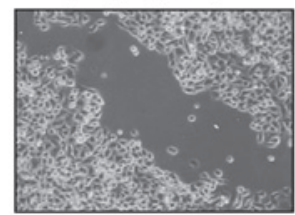

$30 \mathrm{ng} / \mathrm{ml}$ VEGF $(24 \mathrm{~h})$

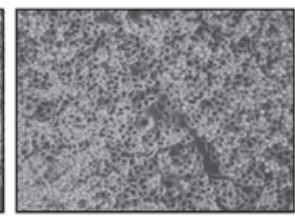

Sanguinarine

$(1.0 \mu \mathrm{M}, 24 \mathrm{~h})$

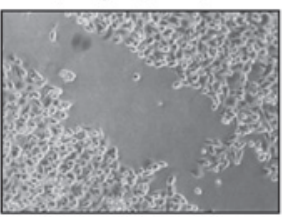

Figure 1. Sanguinarine inhibits VEGF-induced angiogenesis and migration of A549 cells. (A) VEGF (30 ng/ml) was added to the cultures of sub-confluent HMVECs in medium containing indicated concentrations of sanguinarine and then cultured for $24 \mathrm{~h}$. Total length of tubes was observed in 10 randomly selected fields for each dose. Data are representative of the means \pm standard error of the means (SEM) of three independent experiments. (B) Confluent A549 cells cultured in 6-well tissue culture dishes were wounded using sterile pipette tips $(0 \mathrm{~h})$ and then re-cultured in the VEGF-containing medium with or without sanguinarine $(1.0$ or $1.5 \mu \mathrm{M})$. The cells were photographed under a phase contrast microscope $24 \mathrm{~h}$ after wounding. VEGF, vascular endothelial growth factor.
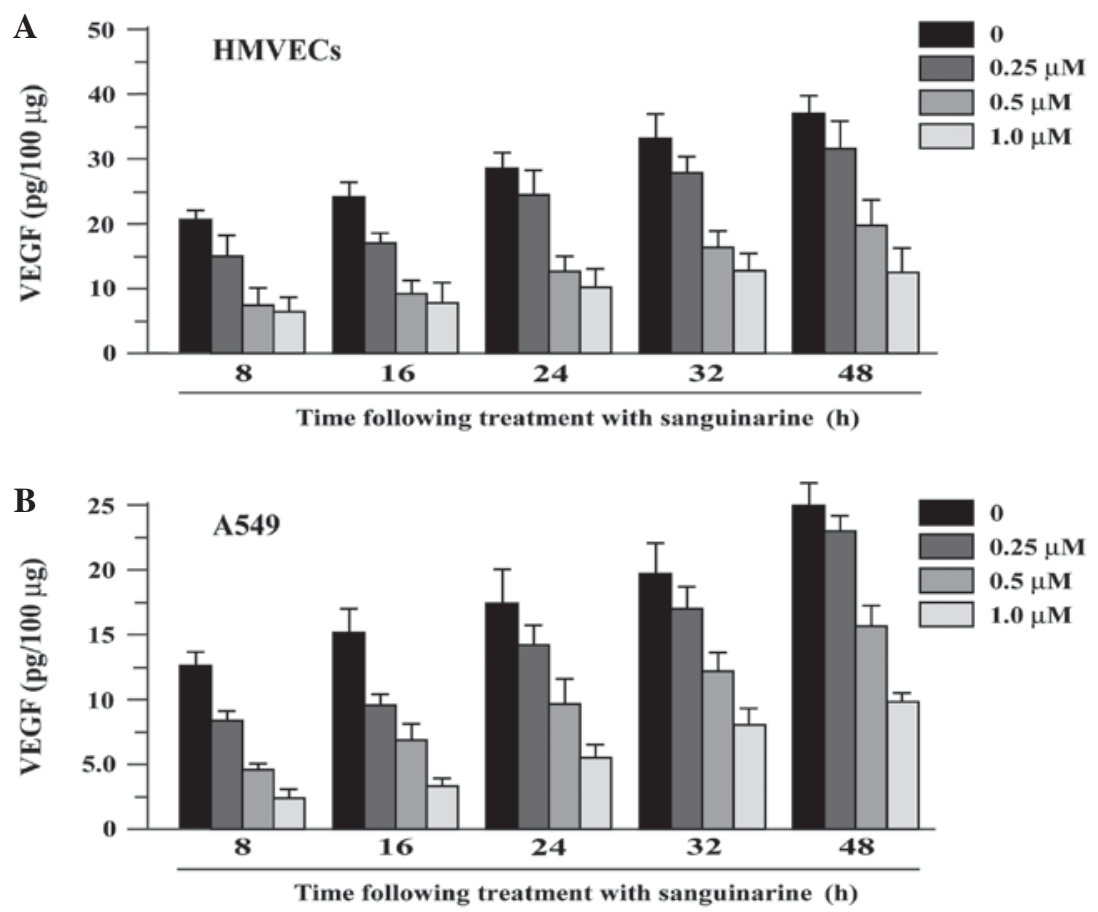

Figure 2. Sanguinarine inhibits VEGF secretion into the conditioned media of (A) HMVECs and (B) A549 cells. The cells were incubated in medium containing the indicated concentrations of sanguinarine for $8-48 \mathrm{~h}$. The levels of VEGF secretion were determined by ELISA and expressed as pg of VEGF/100 $\mu \mathrm{g}$ of the total cell protein content. Data are representative of the means \pm SEM of three independent experiments. HMVEs, human microvascular endothelial cells; VEGF, vascular endothelial growth factor.

and without $1 \mu \mathrm{M}$ sanguinarine for 6,24 or $48 \mathrm{~h}$ and harvested for northern blot analysis. As shown in Fig. 3, a single 3.7-kb VEGF message in RNA isolated from A549 cells was detectable. Moreover, a significant time-dependent elevation of VEGF transcripts was observed in A549 cells cultured in serum-free medium (Fig. 3A). For example, an approximately 6- and 9-fold increase was obtained by serum starvation at 24 and $48 \mathrm{~h}$, respectively $(\mathrm{P}<0.05)$. Moreover, a further increase of VEGF mRNA was determined when the cells were exposed to $0 \% \mathrm{O}_{2}$ (hypoxia) for $24 \mathrm{~h}(\mathrm{P}<0.05)$ (Fig. 3B). However, the increased expression of VEGF by serum starvation $(\mathrm{P}<0.05)$ and hypoxia $(\mathrm{P}<0.01)$ was significantly repressed in the presence of $1 \mu \mathrm{M}$ sanguinarine.

Repression of VEGF promoter activation by sanguinarine. We also examined the impact of sanguinarine on the VEGF promoter activity stimulated by serum starvation and hypoxia in A549 cells transiently transfected with pGL3-VEGF, a VEGF promoter-luciferase-reporter construct. As expected, a dose-dependent reduction of pGL3-VEGF activation by serum starvation (Fig. 4A) or hypoxia (Fig. 4B) was observed in the presence of sanguinarine. For example, $1.0 \mu \mathrm{M}$ sanguinarine 
A
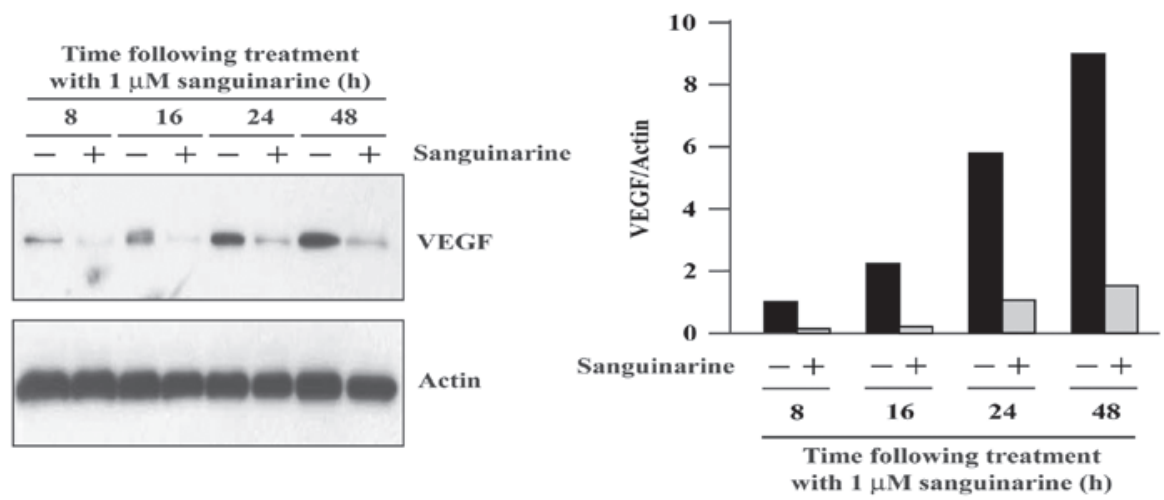

B
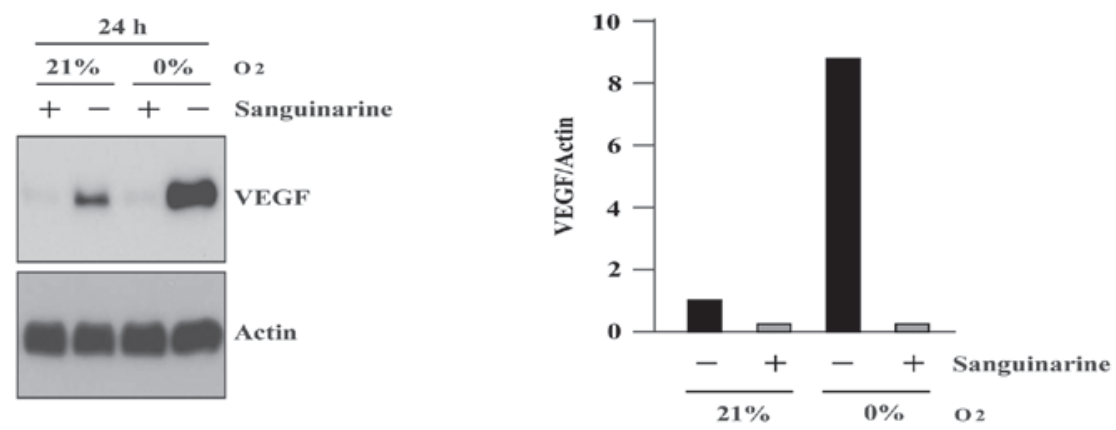

Figure 3. Northern blot analysis of VEGF transcript in human lung cancer cells is shown. (A) A549 cells were cultured in serum-free medium containing $1 \mu \mathrm{M}$ sanguinarine for the indicated time periods. (B) A549 cells in serum-free medium containing $1 \mu \mathrm{M}$ sanguinarine were exposed to a normoxic environment consisting of $21 \% \mathrm{O}_{2} / 5 \% \mathrm{CO}_{2} /$ remainder $\mathrm{N}_{2}$ or to hypoxic conditions with $95 \% \mathrm{~N}_{2} / 5 \% \mathrm{CO}_{2}$ for $24 \mathrm{~h}$. Total RNA was isolated, and northern blot analysis was performed with $30 \mu \mathrm{g}$ of RNA/lane. The filter was first probed with a 32P-VEGF probe followed by a 32P- $\beta$-actin probe. Representative data are shown from three independent experiments. VEGF, vascular endothelial growth factor.

A

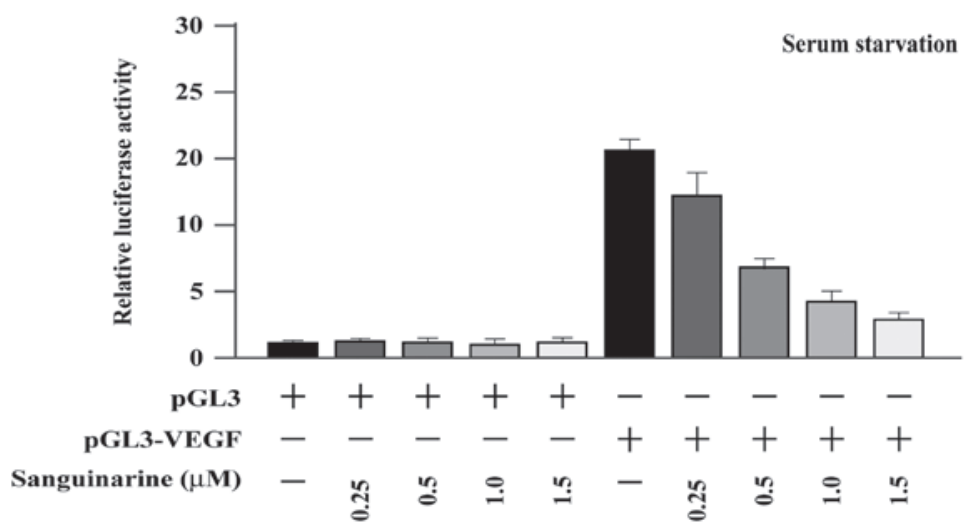

B

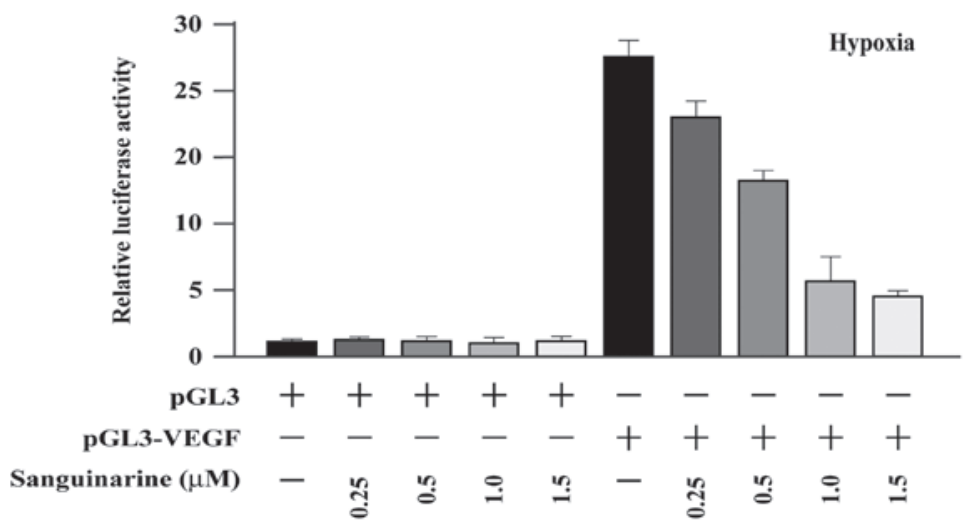

Figure 4. Sanguinarine inhibits VEGF promoter activity. Exponentially growing A549 cells were transfected with pGL3 (as a negative control) or pGL3-VEGF. (A) Transfected cells at $24 \mathrm{~h}$ following transfection were cultured in serum-free medium or (B) were exposed to hypoxic conditions with $95 \% \mathrm{~N}_{2} / 5 \% \mathrm{CO}_{2}$ containing various concentrations of sanguinarine. Values are presented as the means \pm SEM of six replicate wells from three independent experiments. 

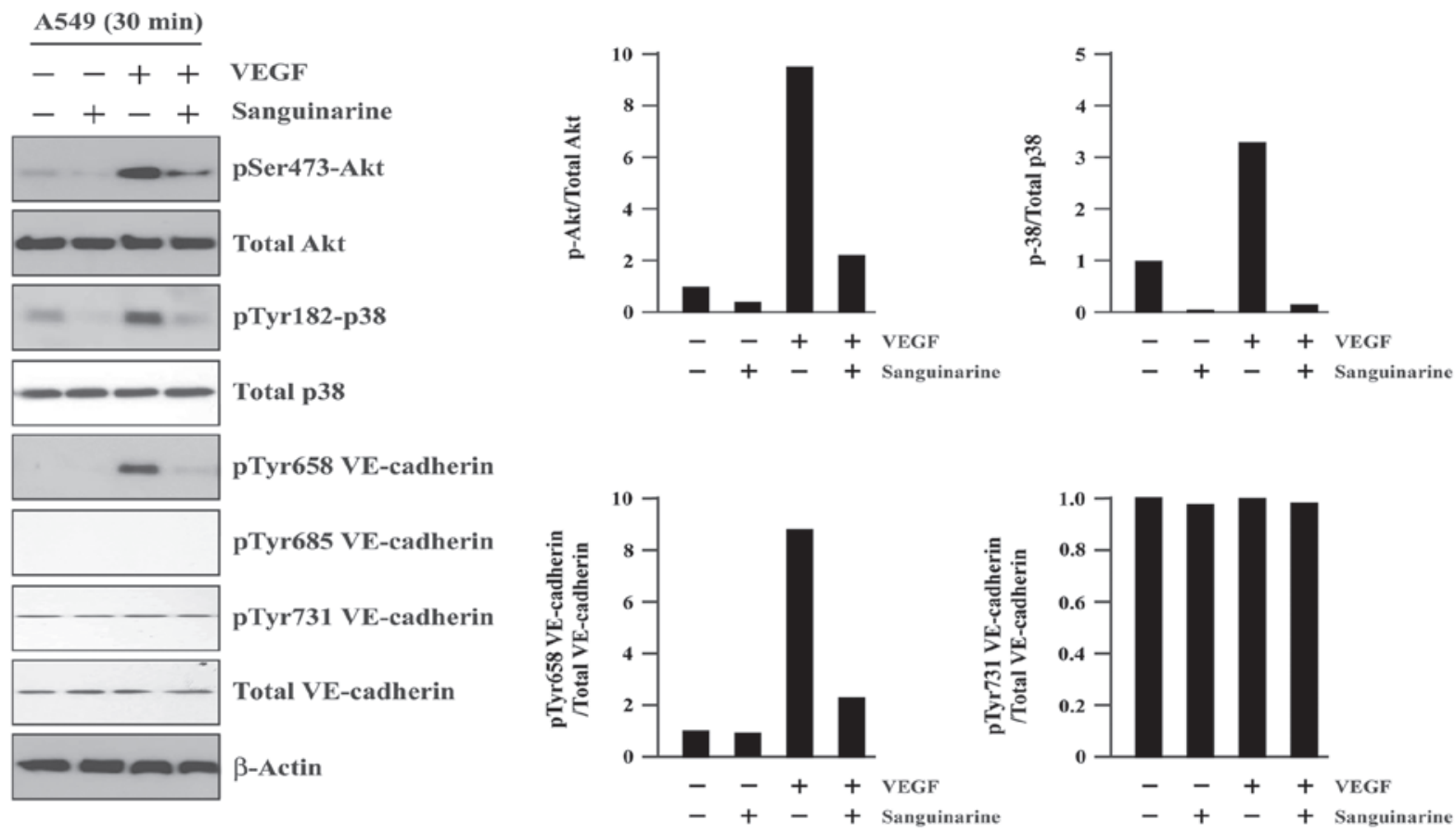

Figure 5. Exponentially growing A549 cells were changed to serum-free medium containing VEGF $(30 \mathrm{ng} / \mathrm{ml}) \pm$ sanguinarine $(1 \mu \mathrm{M})$ for $20 \mathrm{~min}$ and harvested for Western blot assay. Representative data from three independent experiments are shown. VEGF, vascular endothelial growth factor.

resulted in an $\sim 65 \%$ reduction of VEGF activation by serum starvation $(\mathrm{P}<0.05)$ and in an $82 \%$ reduction of VEGF activation by hypoxia $(\mathrm{P}<0.05)$.

Inhibition of VEGF-mediated protein expression by sanguinarine. As shown in Fig. 5, VEGF (20 min exposure) triggered a significant increase of Akt (Ser473), p38 (Tyr182) and VE-cadherin (Tyr658) phosphorylation, and did not affect the expression levels of VE-cadherin phosphorylation at Tyr685 and Tyr731 sites, Akt, p38 and VE-cadherin protein. However, in the presence of $1.0 \mu \mathrm{M}$ sanguinarine, the VEGFmediated phosphorylation activation was markedly reduced or completely inhibited. Ssimilar inhibition findings were also observed in A549 cells treated with $0.5 \mu \mathrm{M}$ sanguinarine (data not shown).

\section{Discussion}

Due to the fact that solid tumors, including lung cancer, are angiogenesis-dependent, the suppression of endothelial cells is likely to result in the inhibition of tumor growth, progression and metastasis. Adhesion molecules, proteases and cytokines are known to be involved in angiogenesis. Among them, the best-studied angiogenic growth factor is VEGF $(1,2)$. VEGF has been demonstrated to bind to the receptor VEGF-R2 and pass the transcriptional signal to the endothelial cells, while also binding to VEGF-R1 to induce endothelial cell-cell interactions and capillary formation. Previous studies demonstrated the effects of sanguinarine on angiogenesis and metastasis. In 2004, Eun and Koh (13) first observed that sanguinarine might inhibit VEGF-induced endothelial cell migration, sprouting and survival in vitro, as well as suppress blood vessel formation in vivo in mouse Matrigel plugs and in the chorioallantoic membrane of the chick embryo model. Subsequently, in their studies, Basini et al (14-16) showed that sanguinarine blocked VEGF-induced vessel growth at $300 \mathrm{nM}$. Findings of additional studies demonstrated that sanguinarine showed a marked antiangiogenic activity in a mouse model of melanoma skin cancer (10). Our findings provide further evidence that sanguinarine inhibits VEGF-mediated angiogenesis, as observed by the tube formation assay of HMVECs. In addition, we demonstrated that sanguinarine strongly inhibited the VEGF-induced migration of human A549 lung cancer cells. Sanguinarine-reduced adhesion and invasive activities were also observed in colon cancer cells of NFKB and breast cancer cells $(19,20)$.

In the present study, we also demonstrated that sanguinarine strongly inhibits VEGF protein secretion in conditioned media with serum starvation in either HMVEC or A549 cells. The sanguinarine inhibition of VEGF was also observed at the level of transcriptional regulation, which was manifested by a significant decrease in transcription levels and in VEGF promoter activation by serum starvation and hypoxia. To the best of our knowledge, these findings indicate for the first time that sanguinarine affects VEGF secretion and expression, as well as having a direct impact on VEGF transcription levels and VEGF promoter activation under various types of stress.

These data also showed that the VEGF-mediated phosphorylation activation of Akt (Ser473), p38 (Tyr182) and VE-cadherin (Tyr658), three modulators in the VEGF signaling pathway, was markedly reduced or blocked by sanguinarine. The inhibitory effects of Akt phosphorylation by sanguinarine were also observed by Basini et al (14-16). Those findings suggested that sanguinarine is able to repress the activation of VEGF signal transduction, and that the suppression of Akt (Ser473), p38 (Tyr182) and that VE-cadherin (Tyr658) phosphorylation activation is critical for the inhibition of VEGF-mediated angiogenesis by sanguinarine. 
These findings provide a mechanistic basis for the antiangiogenic and anti-invasive activity of sanguinarine in lung cancer cells, where sanguinatine, a novel VEGF inhibitor, represses VEGF secretion, expression and transcriptional activation. Current studies are focused on the potential applications of sanguinarine alone or in combination with other VEGF inhibiting anticancer drugs for controlling angiogenesis and metastasis of lung and possibly other types of cancer. In addition, investigations are underway as to whether or not other benz[c]phenanthridine alkaloids, such as chelerythrine, chelidonine, sanguilutine and chelilutine, induce the an inhibition of VEGF transcriptional activity and expression, thereby enhancing their antiangiogenic activities.

\section{Acknowledgements}

This study was supported by grants from the NNSFC (nos. 81071906 and 81172127), the Program for Scientific Innovation Research of College Graduate in Jiangsu (CX10B0452); the Outstanding Doctoral Thesis Project of the Soochow University (233209749), the Medical Scientific Research Project of Soochow University (HZ200905) and the Program for Preliminary Scientific Research of Soochow University (SDY2011A45).

\section{References}

1. Carmeliet P and Jain RK: Molecular mechanisms and clinical applications of angiogenesis. Nature 473: 298-307, 2011.

2. Ebos JM and Kerbel RS: Antiangiogenic therapy: impact on invasion, disease progression, and metastasis. Nat Rev Clin Oncol 8: 210-221, 2011

3. Farhat FS, Tfayli A, Fakhruddin N, et al: Expression, prognostic and predictive impact of VEGF and bFGF in non-small cell lung cancer. Crit Rev Oncol Hematol: Apr 9, 2012 (Epub ahead of print).

4. Das M and Wakelee H: Targeting VEGF in lung cancer. Expert Opin Ther Targets 16: 395-406, 2012.

5. Aggarwal C, Somaiah N and Simon G: Antiangiogenic agents in the management of non-small cell lung cancer: where do we stand now and where are we headed? Cancer Biol Ther 13: 247-263, 2012.
6. Blakely $\mathrm{C}$ and Jahan T: Emerging antiangiogenic therapies for non-small cell lung cancer. Expert Rev Anticancer Ther 11: 1607-1618, 2011.

7. Lind JS and Smit EF: Angiogenesis inhibitors in the treatment of non-small cell lung cancer. Ther Adv Med Oncol 1: 95-107, 2009.

8. Mackraj I, Govender T and Gathiram P: Sanguinarine. Cardiovasc Ther 26: 75-83, 2008.

9. Sun M, Liu C, Nadiminty N, Lou W, et al: Inhibition of Stat3 activation by sanguinarine suppresses prostate cancer cell growth and invasion. Prostate 72: 82-89, 2012.

10. De Stefano I, Raspaglio G and Zannoni GF: Antiproliferative and antiangiogenic effects of the benzophenanthridine alkaloid sanguinarine in melanoma. Biochem Pharmacol 78: 1374-1381, 2009.

11. Tsukamoto H, Kondo S, Mukudai Y, et al: Evaluation of anticancer activities of benzo[c]phenanthridine alkaloid sanguinarine in oral squamous cell carcinoma cell line. Anticancer Res 31: 2841-2946, 2011

12. Jang BC, Park JG and Song DK: Sanguinarine induces apoptosis in A549 human lung cancer cells primarily via cellular glutathione depletion. Toxicol In Vitro 23: 281-287, 2009.

13. Eun JP and Koh GY: Suppression of angiogenesis by the plant alkaloid, sanguinarine. Biochem Biophys Res Commun 317: 618-624, 2004.

14. Basini G, Bussolati S, Santini SE and Grasselli F: Sanguinarine inhibits VEGF-induced angiogenesis in a fibrin gel matrix. Biofactors 29: 11-18, 2007.

15. Basini G, Santini SE, Bussolati S and Grasselli F: Sanguinarine inhibits VEGF-induced Akt phosphorylation. Ann N Y Acad Sci 1095: 371-376, 2007

16. Basini G, Santini SE, Bussolati S and Grasselli F: The plant alkaloid sanguinarine is a potential inhibitor of follicular angiogenesis. J Reprod Dev 53: 573-579, 2007.

17. Pica F, Balestrieri E, Serafino A, et al: Antitumor effects of the benzophenanthridine alkaloid sanguinarine in a rat syngeneic model of colorectal cancer. Anticancer Drugs 23: 32-42, 2012.

18. Fan S, Ma YX and Wang C: p300 modulates the BRCA1 inhibition of estrogen receptor activity. Cancer Res 62: 141-151, 2002.

19. Choi YH, Choi WY, Hong SH, et al: Anti-invasive activity of sanguinarine through modulation of tight junctions and matrix metalloproteinase activities in MDA-MB-231 human breast carcinoma cells. Chem Biol Interact 179: 185-191, 2009.

20. Chang MC, Chan CP, Wang YJ, et al: Induction of necrosis and apoptosis to KB cancer cells by sanguinarine is associated with reactive oxygen species production and mitochondrial membrane depolarization. Toxicol Appl Pharmacol 218: 143-151, 2007. 